\title{
Presentation and management of docetaxel- related adverse effects in patients with breast cancer
}

This article was published in the following Dove Press journal:

Cancer Management and Research

27 May 2014

Number of times this article has been viewed

\author{
Maria Y Ho \\ John R Mackey \\ Division of Medical Oncology, Cross \\ Cancer Institute, Edmonton, AB, \\ Canada
}

\begin{abstract}
The taxane chemotherapeutic agent docetaxel has been utilized in the management of breast cancer in the adjuvant, neoadjuvant and metastatic setting. Although well tolerated by the majority of patients, docetaxel toxicity may limit the dose which can be administered. Adverse events include infusion reactions, febrile neutropenia, fatigue, fluid retention, pneumonitis, cutaneous and nail toxicity, epiphora and lacrimal duct stenosis, gastrointestinal complications, and neuropathies. In this review, we explore these complications and how they can be effectively managed to improve patient quality of life during and following docetaxel therapy.
\end{abstract}

Keywords: toxicity, chemotherapy, adverse events

\section{Introduction}

Docetaxel (Taxotere ${ }^{\circledR}$; Sanofi-Aventis Inc., Laval, QC, Canada) is an important antimicrotubule agent used to treat a variety of solid tumors including breast cancer, where docetaxel-containing regimens improve outcomes for patients in the metastatic, adjuvant, and neoadjuvant settings. This paper will provide an overview of the current roles of docetaxel in the treatment of metastatic and early-stage breast cancer as well as management of common side effects in cancer patients.

\section{Efficacy of docetaxel and benefit to risk assessment in breast cancer}

The use of adjuvant systemic chemotherapy has contributed greatly to the reduction in cause-specific mortality due to breast cancer in the Western Hemisphere. ${ }^{1}$ The decision to use adjuvant chemotherapeutic agents (ie, the administration of cytotoxic treatment following primary surgery) is largely driven by the anticipated risk of breast cancer distant recurrence, as determined by histology of invasive disease, expression of estrogen and/or progesterone receptors, human epidermal growth factor receptor (HER)-2 status, tumor size, nodal status, and age of the patient. ${ }^{2,3}$ In general, adjuvant chemotherapy is considered for patients with hormone-negative breast cancer with tumor size $>0.5 \mathrm{~cm}$ or with pathological node involvement. For those patients with hormone receptor-positive breast cancer, chemotherapeutic agents are usually administered in the setting of pathologically positive lymph nodes, large tumor size, high tumor grade, and the presence of lymphovascular invasion and/or high recurrence score on gene expression recurrence assays. ${ }^{4}$

The taxanes, docetaxel and paclitaxel, are among the most effective single agents in early breast cancer. Clinically meaningful benefits of taxane incorporation in the adjuvant 
setting were affirmed in the Early Breast Cancer Trialists Collaborative Group 2012 meta-analysis for women with newly diagnosed breast cancer. The addition of taxane to anthracycline resulted in a further reduction in the event rate ratio of recurrence of 0.87 , breast cancer mortality of 0.99 , and overall mortality of 0.89 when compared with anthracycline alone. ${ }^{5}$ The benefits of taxane incorporation were independent of age, nodal status, tumor size, tumor grade, and hormone receptor status across clinical trials. As a result, anthracycline- and taxanebased chemotherapeutic regimens have become the standard of care in early stage breast cancers. Among the most active adjuvant chemotherapy regimens, the docetaxel-based combinations of docetaxel, doxorubicin, and cyclophosphamide (TAC), ${ }^{6-8}$ docetaxel with cyclophosphamide, ${ }^{9,10}$ sequential anthracycline (eg, FEC [5-fluorouracil, epirubicin, and cyclophosphamide]) followed by docetaxel monotherapy, ${ }^{11-14}$ and docetaxel, carboplatin, and trastuzumab ${ }^{15}$ are most commonly used.

Similarly, combinations and sequences of anthracycline and taxanes have become the standard of care for preoperative neoadjuvant breast cancer chemotherapy. The value of docetaxel in the preoperative setting was first demonstrated with the Aberdeen study, in which tumor responses and overall survival were improved with sequential anthracyclinedocetaxel when compared with continuing anthracycline chemotherapy. ${ }^{16,17}$

Taxanes also play an important role in the treatment of metastatic breast cancer. The aims of systemic treatment are to palliate symptoms, prolong survival, and maintain quality of life. Even though no prospective randomized controlled clinical trials have shown that systemic chemotherapy improves overall survival versus best supportive care, docetaxel-based trials have demonstrated improved survival outcomes in the setting of metastatic disease when compared with other chemotherapy regimens. ${ }^{18-20}$ The outcomes for patients with metastatic breast cancer have improved significantly over the last two decades, and this is largely attributed to the availability of novel systemic therapies. A large retrospective study published by the British Columbia Agency Breast Tumor Group revealed that patients who were diagnosed with metastatic breast cancer between 1997 and 2001 had a $45 \%$ overall survival rate at 2 years in comparison with those who were diagnosed between 1991 and 1995 with only a 34\% survival rate at 2 years. ${ }^{21}$ Chemotherapy is often the treatment choice for patients with visceral metastases associated with end-organ dysfunction, short disease-free interval, and those with rapidly progressive symptomatic disease given the higher likelihood of achieving a response rate. ${ }^{22}$
Docetaxel has comparable activity to anthracycline in the treatment of metastatic breast cancer. ${ }^{23}$ Taxanes are often the treatment of choice either as single agents or in combination in patients who are at risk for cardiac complications due to prior anthracycline exposure and those who developed metastases less than 12 months after prior anthracycline-based adjuvant therapy. Even though combinations of anthracycline and taxane generate high response rates, they are associated with a higher toxicity rate, with no clear survival advantage over sequential monotherapy. ${ }^{19,24}$ Consequently, combination regimens are generally reserved for patients with rapidly progressive and/or symptomatic visceral disease. Sequential single-agent chemotherapy is the treatment of choice for most patients with metastatic breast cancer due to a reasonable chance of response, successful symptom palliation, and improved quality of life while minimizing toxicities. For the subgroup of patients with hormone-positive disease, endocrine therapy is often used as the initial treatment of choice for those with soft tissue and bone metastases, while chemotherapy is reserved for those with visceral metastases. ${ }^{22}$

For those patients with HER-2-positive metastatic breast cancer, docetaxel has been shown to be synergistic with trastuzumab (the HER-2-directed monoclonal antibody) in preclinical models. ${ }^{25}$ Docetaxel is commonly combined with trastuzumab, where it has demonstrated important survival advantages in combination $^{26,27}$ and, most recently, with the triplet therapy of docetaxel, trastuzumab, and pertuzumab (a monoclonal antibody that prevents HER family dimerization). ${ }^{28}$

\section{Dosing schedules}

Docetaxel has been used in breast cancer therapy in two dosing schedules which differ in toxicity profiles. The original registration regimen, and the most frequent in clinical practice, is intravenous administration at 3-weekly intervals, with a starting dose of between 60 and $100 \mathrm{mg} / \mathrm{m}^{2}$. Weekly intravenous docetaxel schedules are most commonly given day 1 , day 8 , and day 15 every 28-day cycle, with dosing of $25-35 \mathrm{mg} / \mathrm{m}^{2}$. The use of weekly docetaxel schedules is largely restricted to palliation of metastatic disease, where it has been shown to have fewer neutropenic complications than 21-day docetaxel but has somewhat lower anticancer activity and higher rates of skin toxicity and fatigue. ${ }^{14,29,30}$

\section{Presentation of side effects and management of docetaxel- related adverse events}

Docetaxel causes a variety of acute and long-term side effects. Fortunately, most of the common treatment-related 
toxicities, such as infusion reactions, febrile neutropenia, fatigue, and fluid retention are resolved between cycles of treatment or reversible upon treatment discontinuation. Prior to therapy administration, patients are screened for adequate renal function, hepatic function, and bone marrow function to ensure these acute side-effects are resolved. However, peripheral neuropathy is a long-term side effect of taxane chemotherapy that may be debilitating for patients well after completion of treatment.

\section{Acute side effects Infusion reactions}

Docetaxel is one of the cytotoxic agents that frequently triggers acute infusion reactions. These reactions typically occur within minutes or hours of drug administration, with characteristic symptoms including "standard" reactions of flushing, itching, dyspnea, fever, hypoxia, and fever, and "classical hypersensitivity" reactions (ie, angioedema, urticaria, wheezing, stridor, anaphylaxis, and cardiorespiratory arrest). ${ }^{31}$ Hypersensitivity reactions tend to be most severe on rechallenge with the drug. Premedication with glucocorticoids and antihistamines prior to infusion can help to reduce and prevent the severity of reactions, and they are routinely administered to patients prior to docetaxel exposure. Even with premedication, approximately $2 \%$ of patients will experience potentially life-threatening reactions. ${ }^{32,33}$ While both the taxane and the solvent in which the drug is dissolved (polysorbate 80 ) can contribute to infusion reactions, the underlying mechanisms of docetaxel-induced infusion reactions still remain unclear. ${ }^{34-38}$ Symptoms associated with standard infusion reactions and hypersensitivity/allergic reactions have been attributed mainly to cytokine release and mast cell/basophil activation, respectively. Initial management of standard infusion reactions includes temporary cessation of drug infusion for 30 minutes, with administration of additional intravenous antihistamines and glucocorticoids. Upon resolution of symptoms, infusion may be restarted at a slower rate. For anaphylaxis, stabilization of the cardiorespiratory system and use of epinephrine are indication, and discontinuation of drug infusion is usually required.

\section{Febrile neutropenia}

Myelosuppression is one of the most common treatmentrelated toxicities following administration of cytotoxic chemotherapy. Patients receiving combination chemotherapy experience a small to moderate reduction in their white cell count most commonly 10-14 days after initial administration. Febrile neutropenia is defined as an oral temperature $>38.5^{\circ} \mathrm{C}$ or two consecutive readings of $>38.0^{\circ} \mathrm{C}$ for 2 hours with an absolute neutrophil count $<0.5 \times 10^{9} / \mathrm{L} .{ }^{39}$ The condition is associated with significant morbidity and mortality if not managed appropriately. Patients who develop febrile neutropenia are at increased risk of serious infections and often require hospitalization.

In contrast to many chemotherapeutic regimens used in breast cancer therapy, there is a high risk of developing febrile neutropenia with the various docetaxel-containing chemotherapeutic regimens. The cumulative risk of febrile neutropenia ranges from 5\%-25\% with doxorubicin/ cyclophosphamide followed by docetaxel to $21 \%-24 \%$ with adjuvant TAC (docetaxel, doxorubicin, and cyclophosphamide) chemotherapy when these regimens are given without primary prophylaxis with granulocyte colony stimulating factor (G-CSF). The consensus guidelines from the National Comprehensive Cancer Network (NCCN) and the American Society of Clinical Oncology (ASCO) recommend the use of G-CSFs as primary prophylaxis if the risk of toxicity is estimated to be $20 \%$ or more, with the hope of reducing the incidence of neutropenic fever, duration of neutropenia, infectious complications, and rate of hospitalization. ${ }^{40-43}$ Furthermore, secondary prophylaxis is warranted in patients who have developed febrile neutropenia with previous cycles of chemotherapy, particularly in the curative intent setting of (neo)adjuvant therapy where dose reduction may compromise outcome. In the metastatic setting, dose reduction is often instituted after development of febrile neutropenia to minimize future complications.

Treatment of febrile neutropenia typically involves risk assessment, blood cultures, admission into hospital and administration of broad-spectrum intravenous antibiotics, and close clinical monitoring. Even though the use of G-CSFs has been shown to shorten the duration of neutropenia, fever, and length of hospital stay, no survival benefit has been demonstrated. As a result, ESMO (European Society for Medical Oncology), ASCO, and NCCN guidelines recommend against routine use of G-CSFs for patients with established febrile neutropenia. ${ }^{40,41,44}$ However, use of G-CSFs can be considered for patients with highrisk features such as hospital duration $>10$ days, profound neutropenia (with $<100$ cells $/ \mu \mathrm{L}$ ), age $>65$, multiorgan dysfunction, and hypotension.

\section{Fluid retention}

Docetaxel therapy frequently triggers fluid retention presenting as swelling of the extremities, pleural effusions, ascites, and pericardial effusion. One of the proposed 
mechanisms underlying this adverse effect is increased permeability of the capillaries resulting in leakage of fluid into the surrounding tissue. ${ }^{45}$ The severity of this reaction is proportional to the cumulative dose of the drug administered. Premedication with glucocorticoid starting 24 hours prior and 48 hours following each docetaxel dose decreases the rate of fluid retention from $20 \%$ to $6 \%$ and increases the tolerability of this drug among patients. ${ }^{46}$ Studies have indicated that a single dose of dexamethasone, rather than the standard 3 doses, may be sufficient to prevent docetaxelfluid retention. ${ }^{47,48}$ Patients should be advised to monitor for signs of increased fluid accumulation in their fingers, ankles, and mid-abdominal areas. Treatment with diuretics may provide symptomatic relief and limit the severity of fluid retention. ${ }^{49}$

\section{Cutaneous toxicity}

Docetaxel is also known to cause a skin toxicity known as acral erythema. It often starts with a tingling sensation in the palms and soles, followed by tenderness and edema. Occasional desquamation and blistering in the affected area may also occur. The pathogenesis of acral erythema remains unclear. Proposed mechanisms include immunoglobulin E-mediated type 1 reaction and direct toxic effect of chemotherapy on the eccrine sweat glands. ${ }^{50}$ Treatment of acral erythema mainly includes cessation of drug and symptomatic treatment to relieve the painful swelling and erythema. In addition, intravenous docetaxel has also been associated with a specific variant of acral erythema known as erythrodysesthesia plaque that presents as a fixed, solitary plaque proximal to the infusion site without involvement of the palms and soles. The characteristic lesion typically resolves with desquamation followed by hyperpigmentation weeks after the initial insult. ${ }^{51,52}$

\section{Nail toxicity}

Docetaxel can cause a wide range of nail toxicities including subungual and splinter hemorrhages, hyperkeratosis, paronychia, separation of the nail from the nail bed, and cessation of nail growth. The severity of the nail changes correlates with the total number of chemotherapy cycles and the cumulative dose of chemotherapy administered. Studies have indicated that the use of frozen gloves and socks can slow the onset and lower the severity of symptoms in a large proportion of patients by reducing blood flow to the affected areas. ${ }^{53,54}$ The majority of the symptoms resolve spontaneously within 6-12 months after chemotherapy discontinuation.

\section{Pneumonitis}

Docetaxel has been rarely reported to cause acute, bilateral interstitial lung disease that can occur during, within a few hours, or up to weeks after initial administration. Symptoms include exertional dyspnea, dry cough, malaise, and fever. ${ }^{55}$ The mechanism behind interstitial pneumonitis is not well understood at the present time. Some researchers believe that it is predominantly a lymphocyte-mediated immune reaction. ${ }^{33}$ In contrast to paclitaxel, the incidence of pulmonary toxicity is proportional to the total dose of docetaxel administered. In a Phase III trial of women with advanced breast cancer, a statistically significant higher rate of pulmonary toxicity was observed with higher docetaxel doses $\left(100 \mathrm{mg} / \mathrm{m}^{2}\right.$ in comparison with $\left.60 \mathrm{mg} / \mathrm{m}^{2}\right) .{ }^{56}$ Moreover, a higher incidence of pneumonitis was seen in patients receiving weekly versus every 3 weeks docetaxel regimen. ${ }^{57}$ The rate of pulmonary toxicity is also higher when docetaxel is given in combination with gemcitabine or radiation. ${ }^{58-60}$ Patients with preexisting lung disease are at a higher risk of developing pulmonary complications with docetaxel treatment. Therefore, taxane treatment is relatively contraindicated in patients with preexisting lung disease. ${ }^{61}$ Fortunately, most cases resolve with supportive care and discontinuation of taxane therapy. For patients with clinical signs of oxygen desaturation or impending respiratory failure, an empiric trial of glucocorticoids may be warranted.

\section{Fatigue}

Most patients receiving docetaxel chemotherapy will experience fatigue during the course of their treatment. Research indicates that continuous exercise may help to delay the onset of fatigue and optimize physical function. ${ }^{62,63}$ To date, no studies have been conducted on the management of docetaxel-related fatigue. Other common causes of asthenia such as depression, pain, anemia, and hypothyroidism must also be considered and treated accordingly.

\section{Epiphora and lacrimal duct stenosis}

Epiphora (excessive tearing) is a frequent complaint of breast cancer patients receiving docetaxel. Although most patients treated with short courses of adjuvant docetaxel find this is a self-limited problem that resolves soon after completion of docetaxel chemotherapy, it is particularly frequent and severe in those receiving prolonged docetaxel therapy in the metastatic setting and those treated with weekly docetaxel. In some cases, canalicular fibrosis requiring surgical stenting has been identified. ${ }^{64-66}$ 


\section{Gastrointestinal complications}

Cases of gastrointestinal perforation, and dehydration as a consequence of enterocolitis, colitis, and neutropenic enterocolitis have been reported in breast cancer patients receiving docetaxel. Patients receiving this agent should be carefully evaluated if severe diarrhea or new onset abdominal pain occurs, and surgical consultation is warranted in patients with severe enterocolitis or demonstrated perforation. ${ }^{67,68}$

\section{Long term side effects Neuropathies}

Two of the most common long-term side effects of docetaxel chemotherapy are sensory and motor peripheral neuropathy. Fortunately, the incidence of both of these is much less than paclitaxel. Grade 3 and 4 neuropathy is only observed in less than $10 \%$ of patients receiving docetaxel therapy. ${ }^{69,70}$ Major clinical symptoms include numbness and tingling of the hands and feet, with loss of reflexes. The incidence of neuropathy is dependent upon the total dose of the drug administered. In the Phase III clinical trial of metastatic breast cancer patients treated with docetaxel, neuropathy of grade 2 or greater began at a dosage of $371 \mathrm{mg} / \mathrm{m}^{2} .^{71}$ The mainstay of treatment includes prompt recognition of onset of symptoms with subsequent delay of therapy or dose reduction. Unfortunately, none of the pharmaceutical agents have demonstrated efficacy in the prevention and treatment of taxane-induced neuropathy. Anticonvulsants such as gabapentin may be useful in providing symptomatic relief. ${ }^{72}$

\section{Conclusion}

Docetaxel is an effective chemotherapeutic agent for the treatment of breast cancer in the adjuvant, neoadjuvant, and metastatic settings. Its widespread use has contributed to improvements in breast cancer-specific survival seen in many developed countries. Even though the drug can cause a wide range of toxicities, most of them are treatable with supportive care and cessation of the chemotherapeutic agent. The decision to initiate chemotherapy should always be made in partnership with the patient, who should be fully informed about the potential side effects of the treatment.

\section{Disclosure}

The authors have no conflicts of interest to disclose.

\section{References}

1. Berry DA, Cronin KA, Plevritis SK, et al. Effect of screening and adjuvant therapy on mortality from breast cancer. $N$ Engl $J$ Med. 2005;353(17):1784-1792.
2. Howlader N, Noone AM, Krapcho M, et al (eds). The Surveillance, Epidemiology, and End Results (SEER) Cancer Statistics Review, 1975-2008, National Cancer Institute. Bethesda, MD, 2010. Available from: http:// seer.cancer.gov/csr/1975_2008/index.html. Accessed May 10, 2014.

3. van der Hage JA, Mieog JS, van de Velde CJ, Putter H, Bartelink H, van de Vijver MJ. Impact of established prognostic factors and molecular subtype in very young breast cancer patients: pooled analysis of four EORTC randomized controlled trials. Breast Cancer Res. 2011;13(3):R68.

4. Albain KS, Barlow WE, Shak S, et al. Prognostic and predictive value of the 21-gene recurrence score assay in postmenopausal women with node-positive, oestrogen-receptor-positive breast cancer on chemotherapy: a retrospective analysis of a randomised trial. Lancet Oncol. 2010;11(1):55-65.

5. Peto R, Davies C, Godwin J; Early Breast Cancer Trialists' Collaborative Group (EBCTCG). Comparisons between different polychemotherapy regimens for early breast cancer: meta-analyses of long-term outcome among 100,000 women in 123 randomised trials. Lancet. 2012;379(9814):432-444.

6. Mackey JR, Martin M, Pienkowski T, et al. Adjuvant docetaxel, doxorubicin, and cyclophosphamide in node-positive breast cancer: 10-year follow-up of the Phase 3 randomised BCIRG 001 trial. Lancet Oncol. 2013;14(1):72-80.

7. Martin M, Pienkowski T, Mackey J, et al. Adjuvant docetaxel for nodepositive breast cancer. $N$ Engl J Med. 2005;352(22):2302-2313.

8. Swain SM, Land SR, Ritter MW, et al. Amenorrhea in premenopausal women on the doxorubicin-and-cyclophosphamide-followed-bydocetaxel arm of NSABP B-30 trial. Breast Cancer Res Treat. 2009;113(2):315-320.

9. Jones S, Holmes FA, O'Shaughnessy J, et al. Docetaxel with cyclophosphamide is associated with an overall survival benefit compared with doxorubicin and cyclophosphamide: 7-year follow-up of US Oncology Research Trial 9735. J Clin Oncol. 2009;27(8):1177-1183.

10. Jones SE, Savin MA, Holmes FA, et al. Phase III trial comparing doxorubicin plus cyclophosphamide with docetaxel plus cyclophosphamide as adjuvant therapy for operable breast cancer. J Clin Oncol. 2006;24(34):5381-5387.

11. Coudert B, Asselain B, Campone M, et al. Extended benefit from sequential administration of docetaxel after standard fluorouracil, epirubicin, and cyclophosphamide regimen for node-positive breast cancer: the 8-year follow-up results of the UNICANCER-PACS01 trial. Oncologist. 2012;17(7):900-909.

12. Eiermann W, Pienkowski T, Crown J, et al. Phase III study of doxorubicin/cyclophosphamide with concomitant versus sequential docetaxel as adjuvant treatment in patients with human epidermal growth factor receptor 2-normal, node-positive breast cancer: BCIRG-005 trial. J Clin Oncol. 2011;29(29):3877-3884.

13. Roche H, Fumoleau P, Spielmann M, et al. Sequential adjuvant epirubicin-based and docetaxel chemotherapy for node-positive breast cancer patients: the FNCLCC PACS 01 Trial. J Clin Oncol. 2006;24(36): 5664-5671.

14. Sparano JA, Wang M, Martino S, et al. Weekly paclitaxel in the adjuvant treatment of breast cancer. N Engl J Med. 2008;358(16):1663-1671.

15. Slamon D, Eiermann W, Robert N, et al. Adjuvant trastuzumab in HER2positive breast cancer. N Engl J Med. 2011;365(14):1273-1283.

16. Heys SD, Hutcheon AW, Sarkar TK, et al. Neoadjuvant docetaxel in breast cancer: 3-year survival results from the Aberdeen trial. Clin Breast Cancer. 2002;3 Suppl 2:S69-S74.

17. Smith IC, Heys SD, Hutcheon AW, et al. Neoadjuvant chemotherapy in breast cancer: significantly enhanced response with docetaxel. J Clin Oncol. 2002;20(6):1456-1466.

18. Nabholtz JM, Falkson C, Campos D, et al. Docetaxel and doxorubicin compared with doxorubicin and cyclophosphamide as first-line chemotherapy for metastatic breast cancer: results of a randomized, multicenter, Phase III trial. J Clin Oncol. 2003;21(6):968-975.

19. Piccart-Gebhart MJ, Burzykowski T, Buyse M, et al. Taxanes alone or in combination with anthracyclines as first-line therapy of patients with metastatic breast cancer. J Clin Oncol. 2008;26(12):1980-1986. 
20. Ravdin PM, Burris HA 3rd, Cook G, et al. Phase II trial of docetaxel in advanced anthracycline-resistant or anthracenedione-resistant breast cancer. J Clin Oncol. 1995;13(12):2879-2885.

21. Chia SK, Speers CH, D'Yachkova Y, et al. The impact of new chemotherapeutic and hormone agents on survival in a population-based cohort of women with metastatic breast cancer. Cancer. 2007;110(5):973-979.

22. Wilcken N, Hornbuckle J, Ghersi D. Chemotherapy alone versus endocrine therapy alone for metastatic breast cancer. Cochrane Database Syst Rev. 2003;(2):CD002747.

23. Chan S, Friedrichs K, Noel D, et al. Prospective randomized trial of docetaxel versus doxorubicin in patients with metastatic breast cancer. J Clin Oncol. 1999;17(8):2341-2354.

24. Verma S, Maraninchi D, O'Shaughnessy J, et al. Capecitabine plus docetaxel combination therapy. Cancer. 2005;103(12):2455-2465.

25. Pegram MD, Konecny GE, O’Callaghan C, Beryt M, Pietras R, Slamon DJ. Rational combinations of trastuzumab with chemotherapeutic drugs used in the treatment of breast cancer. J Natl Cancer Inst. 2004;96(10):739-749.

26. Marty M, Cognetti F, Maraninchi D, et al. Randomized phase II trial of the efficacy and safety of trastuzumab combined with docetaxel in patients with human epidermal growth factor receptor 2-positive metastatic breast cancer administered as first-line treatment: the M77001 study group. J Clin Oncol. 2005;23(19):4265-4274.

27. Valero V, Forbes J, Pegram MD, et al. Multicenter phase III randomized trial comparing docetaxel and trastuzumab with docetaxel, carboplatin, and trastuzumab as first-line chemotherapy for patients with HER2gene-amplified metastatic breast cancer (BCIRG 007 study): two highly active therapeutic regimens. J Clin Oncol. 2011;29(2):149-156.

28. Baselga J, Cortes J, Kim SB, et al. Pertuzumab plus trastuzumab plus docetaxel for metastatic breast cancer. $N$ Engl J Med. 2012;366(2): 109-119.

29. Schroder CP, de Munck L, Westermann AM, et al. Weekly docetaxel in metastatic breast cancer patients: no superior benefits compared to three-weekly docetaxel. Eur J Cancer. 2011;47(9):1355-1362.

30. Stemmler HJ, Harbeck N, Groll de Rivera I, et al. Prospective multicenter randomized Phase III study of weekly versus standard docetaxel (D2) for first-line treatment of metastatic breast cancer. Oncology. 2010;79(3-4):197-203.

31. Syrigou E, Dannos I, Kotteas E, et al. Hypersensitivity reactions to docetaxel: retrospective evaluation and development of a desensitization protocol. Int Arch Allergy Immunol. 2011;156(3):320-324.

32. Schrijvers D, Wanders J, Dirix L, et al. Coping with toxicities of docetaxel (Taxotere). Ann Oncol. Aug 1993;4(7):610-611.

33. Wang GS, Yang KY, Perng RP. Life-threatening hypersensitivity pneumonitis induced by docetaxel (Taxotere). Br J Cancer. 2001;85(9): 1247-1250.

34. Ardavanis A, Tryfonopoulos D, Yiotis I, Gerasimidis G, Baziotis N, Rigatos G. Non-allergic nature of docetaxel-induced acute hypersensitivity reactions. Anticancer Drugs. 2004;15(6):581-585.

35. Eschalier A, Lavarenne J, Burtin C, Renoux M, Chapuy E, Rodriguez M. Study of histamine release induced by acute administration of antitumor agents in dogs. Cancer Chemother Pharmacol. 1988;21(3):246-250.

36. Fossella FV, Lee JS, Murphy WK, et al. Phase II study of docetaxel for recurrent or metastatic non-small-cell lung cancer. J Clin Oncol. 1994;12(6):1238-1244.

37. Szebeni J, Muggia FM, Alving CR. Complement activation by Cremophor EL as a possible contributor to hypersensitivity to paclitaxel: an in vitro study. J Natl Cancer Inst. 1998;90(4):300-306.

38. Weiss RB, Donehower RC, Wiernik PH, et al. Hypersensitivity reactions from taxol. J Clin Oncol. 1990;8(7):1263-1268.

39. Freifeld AG, Bow EJ, Sepkowitz KA, et al. Clinical practice guideline for the use of antimicrobial agents in neutropenic patients with cancer: 2010 update by the Infectious Diseases Society of America. Clin Infect Dis. 2011;52(4):427-431.

40. National Comprehensive Cancer Network. NCCN Clinical practice guidelines in oncology (NCCN Guidelines). Breast Cancer. Version 1. 2014. Available from: http://www.nccn.org/professionals/physician_ gls/f_guidelines.asp\#breast.
41. Aapro MS, Bohlius J, Cameron DA, et al. 2010 update of EORTC guidelines for the use of granulocyte-colony stimulating factor to reduce the incidence of chemotherapy-induced febrile neutropenia in adult patients with lymphoproliferative disorders and solid tumours. Eur $J$ Cancer. 2011;47(1):8-32.

42. Aarts MJ, Peters FP, Mandigers CM, et al. Primary granulocyte colony-stimulating factor prophylaxis during the first two cycles only or throughout all chemotherapy cycles in patients with breast cancer at risk for febrile neutropenia. J Clin Oncol. 2013;31(34): 4290-4296.

43. Martin M, Lluch A, Segui MA, et al. Toxicity and health-related quality of life in breast cancer patients receiving adjuvant docetaxel, doxorubicin, cyclophosphamide (TAC) or 5-fluorouracil, doxorubicin and cyclophosphamide (FAC): impact of adding primary prophylactic granulocyte-colony stimulating factor to the TAC regimen. Ann Oncol. 2006;17(8):1205-1212.

44. Smith TJ, Khatcheressian J, Lyman GH, et al. 2006 update of recommendations for the use of white blood cell growth factors: an evidence-based clinical practice guideline. J Clin Oncol. 2006;24(19):3187-3205.

45. Semb KA, Aamdal S, Oian P. Capillary protein leak syndrome appears to explain fluid retention in cancer patients who receive docetaxel treatment. J Clin Oncol. 1998;16(10):3426-3432.

46. Piccart MJ, Klijn J, Paridaens R, et al. Corticosteroids significantly delay the onset of docetaxel-induced fluid retention: final results of a randomized study of the European Organization for Research and Treatment of Cancer Investigational Drug Branch for Breast Cancer. J Clin Oncol. 1997;15(9):3149-3155.

47. Chouhan JD, Herrington JD. Single premedication dose of dexamethasone $20 \mathrm{mg}$ IV before docetaxel administration. J Oncol Pharm Pract. 2011;17(3):155-159.

48. Montoya ME, Markowitz AB, Klementich F, Palacio D. Docetaxel and fluid retention: use of single-dose dexamethasone. J Clin Oncol. 2007;25(18S):19635

49. Singer EA, Srinivasan R. Intravenous therapies for castration-resistant prostate cancer: toxicities and adverse events. Urol Oncol. 2012; 30(Suppl 4):S15-S19.

50. Eich D, Scharffetter-Kochanek K, Eich HT, Tantcheva-Poor I, Krieg T. Acral erythrodysesthesia syndrome caused by intravenous infusion of docetaxel in breast cancer. Am J Clin Oncol. 2002;25(6): 599-602.

51. Chew L, Chuen VS. Cutaneous reaction associated with weekly docetaxel administration. J Oncol Pharm Pract. 2009;15(1): 29-34.

52. Chu CY, Yang CH, Yang CY, Hsiao GH, Chiu HC. Fixed erythrodysaesthesia plaque due to intravenous injection of docetaxel. Br J Dermatol. 2000;142(4):808-811.

53. Can G, Aydiner A, Cavdar I. Taxane-induced nail changes: predictors and efficacy of the use of frozen gloves and socks in the prevention of nail toxicity. Eur J Oncol Nurs. 2012;16(3):270-275.

54. Scotte F, Tourani JM, Banu E, et al. Multicenter study of a frozen glove to prevent docetaxel-induced onycholysis and cutaneous toxicity of the hand. J Clin Oncol. 2005;23(19):4424-4429.

55. Ochoa R, Bejarano PA, Gluck S, Montero AJ. Pneumonitis and pulmonary fibrosis in a patient receiving adjuvant docetaxel and cyclophosphamide for stage 3 breast cancer: a case report and literature review. J Med Case Rep. 2012;6(1):413.

56. Harvey V, Mouridsen H, Semiglazov V, et al. Phase III trial comparing three doses of docetaxel for second-line treatment of advanced breast cancer. J Clin Oncol. 2006;24(31):4963-4970.

57. Chen YM, Shih JF, Perng RP, Tsai CM, Whang-Peng J. A randomized trial of different docetaxel schedules in non-small cell lung cancer patients who failed previous platinum-based chemotherapy. Chest. 2006;129(4):1031-1038.

58. Katakami N, Takiguchi Y, Yoshimori K, et al. Docetaxel in combination with either cisplatin or gemcitabine in unresectable non-small cell lung carcinoma: a randomized Phase II study by the Japan Lung Cancer Cooperative Clinical Study Group. J Thorac Oncol. 2006;1(5): $447-453$. 
59. Nakamura M, Koizumi T, Hayasaka M, et al. Cisplatin and weekly docetaxel with concurrent thoracic radiotherapy for locally advanced stage III non-small-cell lung cancer. Cancer Chemother Pharmacol. 2009;63(6):1091-1096.

60. Onishi H, Kuriyama K, Yamaguchi M, et al. Concurrent two-dimensional radiotherapy and weekly docetaxel in the treatment of stage III nonsmall cell lung cancer: a good local response but no good survival due to radiation pneumonitis. Lung Cancer. 2003;40(1):79-84.

61. Tamiya A, Naito T, Miura S, et al. Interstitial lung disease associated with docetaxel in patients with advanced non-small cell lung cancer. Anticancer Res. 2012;32(3):1103-1106.

62. Courneya KS, Segal RJ, Mackey JR, et al. Effects of aerobic and resistance exercise in breast cancer patients receiving adjuvant chemotherapy: a multicenter randomized controlled trial. J Clin Oncol. 2007;25(28):4396-4404.

63. Monga U, Garber SL, Thornby J, et al. Exercise prevents fatigue and improves quality of life in prostate cancer patients undergoing radiotherapy. Arch Phys Med Rehabil. 2007;88(11):1416-1422.

64. Chan A, Su C, de Boer RH, Gajdatsy A. Prevalence of excessive tearing in women with early breast cancer receiving adjuvant docetaxel-based chemotherapy. J Clin Oncol. 2013;31(17):2123-2127.

65. Esmaeli B, Amin S, Valero V, et al. Prospective study of incidence and severity of epiphora and canalicular stenosis in patients with metastatic breast cancer receiving docetaxel. J Clin Oncol. 2006;24(22): 3619-3622.
66. Esmaeli B, Valero V. Epiphora and canalicular stenosis associated with adjuvant docetaxel in early breast cancer: is excessive tearing clinically important? J Clin Oncol. 2013;31(17):2076-2077.

67. Bremer CT, Monahan BP. Necrotizing enterocolitis in neutropenia and chemotherapy: a clinical update and old lessons relearned. Curr Gastroenterol Rep. 2006;8(4):333-341.

68. Davila ML. Neutropenic enterocolitis. Curr Opin Gastroenterol. 2006;22(1):44-47.

69. Lee JJ, Swain SM. Peripheral neuropathy induced by microtubulestabilizing agents. J Clin Oncol. 2006;24(10):1633-1642.

70. Rivera E, Mejia JA, Arun BK, et al. Phase 3 study comparing the use of docetaxel on an every-3-week versus weekly schedule in the treatment of metastatic breast cancer. Cancer. 2008;112(7):1455-1461.

71. Jones SE, Erban J, Overmoyer B, et al. Randomized Phase III study of docetaxel compared with paclitaxel in metastatic breast cancer. J Clin Oncol. 2005;23(24):5542-5551.

72. Rao RD, Michalak JC, Sloan JA, et al. Efficacy of gabapentin in the management of chemotherapy-induced peripheral neuropathy: a Phase 3 randomized, double-blind, placebo-controlled, crossover trial (N00C3). Cancer. 2007;110(9):2110-2118.
Cancer Management and Research

\section{Publish your work in this journal}

Cancer Management and Research is an international, peer-reviewed open access journal focusing on cancer research and the optimal use of preventative and integrated treatment interventions to achieve improved outcomes, enhanced survival and quality of life for the cancer patient The journal welcomes original research, clinical \& epidemiological

\section{Dovepress}

studies, reviews \& evaluations, guidelines, expert opinion \& commentary, case reports \& extended reports. The manuscript management system is completely online and includes a very quick and fair peerreview system, which is all easy to use. Visit http://www.dovepress.com/ testimonials.php to read real quotes from published authors. 